\title{
Prospective Multicenter Randomized Phase III Study of Weekly versus Standard Docetaxel plus Doxorubicin (D4) for First-Line Treatment of Metastatic Breast Cancer
}

\author{
Hans-Joachim Stemmler ${ }^{a} \quad$ Nadia Harbeck $^{c} \quad$ Isolde Gröll de Rivera ${ }^{\mathrm{e}}$ \\ Ursula Vehling Kaiser $^{f}$ Gerhard Rauthe ${ }^{g}$ Wolfgang Abenhardt ${ }^{d}$ Almut Artmann ${ }^{c}$ \\ Harald Sommer $^{\mathrm{b}}$ Hans-Gerd Meerpohl ${ }^{\mathrm{h}}$ Marion Kiechle Volker Heinemann $^{\mathrm{a}}$ \\ ${ }^{a}$ Department of Internal Medicine III, Klinikum Grosshadern, and b Department of Gynaecology and Obstetrics, \\ Klinikum Innenstadt, Ludwig Maximilian University of Munich, 'Department of Gynaecology and Obstetrics, \\ Technische Universität München, and d Onkologische Praxis, Munich, ${ }^{e}$ Department of Gynaecology and Obstetrics, \\ Klinikum Ebersberg, Ebersberg, ${ }^{f}$ Onkologische Praxis, Landshut, ${ }^{9}$ Department of Gynaecology and Obstetrics, \\ Schlossbergklinik Oberstaufen, Oberstaufen, and h Department of Gynaecology and Obstetrics, \\ St.-Vincenzius-Kliniken AG, Karlsruhe, Germany
}

\section{Key Words}

Docetaxel - Weekly application - Metastatic breast cancer • Combination chemotherapy

\begin{abstract}
Purpose: Previous phase II studies have indicated a greatly reduced hematotoxicity of docetaxel-based regimens administered on weekly schedules. The present trial was initiated to compare the toxicity and efficacy of weekly docetaxel versus its standard 3-weekly application in combination with doxorubicin. Methods: Patients previously untreated with chemotherapy for metastatic disease were recruited. Inclusion criteria were age $<65$ years or a Karnofsky Performance Status of $70-100 \%$. All patients in the D4 study received doxorubicin $\left(50 \mathrm{mg} / \mathrm{m}^{2}\right)$ on the first day of treatment in addition to docetaxel given either at a 3-weekly dose of 75 $\mathrm{mg} / \mathrm{m}^{2}$ every 3 weeks (q3w) or at a weekly dose of $35 \mathrm{mg} / \mathrm{m}^{2}$ (days 1, 8, and 15; q4w). Treatment was continued until a maximum of 8 cycles, unacceptable toxicity, or disease pro-
\end{abstract}

gression. All patients received standard corticosteroid prophylaxis. Results: Since interim analysis showed failure to reach a significant difference for the primary endpoint (hematotoxicity, i.e. leukopenia), the study was closed according to the study protocol (85 of 242 patients). A lower-thanexpected rate of leukopenia $\geq$ grade 3 was observed in the standard arm of the D4 study compared to the weekly schedule (per-patient analysis: $61.9 \%$ q3w vs. $65.1 \%$ q1w; p > 0.05). Grade 3 and grade 4 fever, diarrhea, and infections occurred more frequently in the standard arm, whereas neurotoxicity and skin/nail disorders were observed more frequently in the weekly arm. Except for fever, none of these differences reached a level of significance. Dose delays, dose reductions, and the rate of omitted doses were increased in the weekly $\mathrm{arm}$. The overall response rate was $44.2 \%$ in the weekly arm compared to $52.4 \%$ in the standard arm $(p=0.52)$. Time to progression was $6.2(q 1 w)$ versus $10.3(q 3 w)$ months $(p=$

H.-J.S. and N.H. contributed equally to this paper.

\section{KARGER}

Fax +4161306 1234 E-Mail karger@karger.ch www.karger.com
(C) 2011 S. Karger AG, Basel

0030-2414/10/0794-0204\$26.00/0

Accessible online at:

www.karger.com/ocl
PD Dr. H.J. Stemmler, Medical Department III (Hematology-Oncology)

Klinikum Grosshadern, University of Munich

Marchioninistrasse 15, DE-81377 Munich (Germany)

Tel. +49897095 3026, Fax +498970958828

E-Mail Joachim.Stemmler@med.uni-muenchen.de 
0.36), and overall survival was 20.5 (q1w) versus 28.7 (q3w) months ( $p=0.98)$. Conclusion: The present data support the feasibility of both weekly and 3-weekly application of docetaxel in combination with doxorubicin. Nevertheless, given that leukopenia was similar in both arms and the efficacy parameters were at least numerically inferior with the weekly schedule, standard 3-weekly application seems to be preferable for patients requiring combination chemotherapy.

Copyright ๑ 2011 S. Karger AG, Basel

\section{Introduction}

Docetaxel (Taxotere ${ }^{\circledR}$; Sanofi-Aventis, Frankfurt, Germany) is one of the most effective antitumor agents currently available for the treatment of early breast cancer as well as metastatic breast cancer (MBC). In MBC, when compared with the gold standard doxorubicin, docetaxel has shown a significantly superior response rate (RR; 47.8 vs. $33.3 \% ; \mathrm{p}=0.008)$ and a trend towards a prolonged time to progression (TTP; 26 weeks vs. 21 weeks) [1]. After failure with anthracycline-containing chemotherapy, single-agent docetaxel has demonstrated superior results when compared with mitomycin/vinblastine [RR, TTP, and overall survival (OS)] or methotrexate/5-fluorouracil (RR and TTP), and it has shown equivalent efficacy when compared with vinorelbine/5-fluorouracil (RR, TTP, and OS) [2-4].

When docetaxel is administered at a standard dose of $100 \mathrm{mg} / \mathrm{m}^{2}$ [every 3 weeks (q3w)], 70-90\% of patients develop grade $3 / 4$ neutropenia [1]. Instead of dose reductions, one strategy to reduce toxicity without growth factor support is to apply docetaxel on a weekly schedule. Several studies have indicated that severe hematotoxicity (grade 3/4) could largely be prevented at weekly doses of less than $40 \mathrm{mg} / \mathrm{m}^{2}$ without impaired efficacy in the first- or secondline setting [5-9]. Moreover, the favorable toxicity profile of weekly scheduled docetaxel was confirmed in 2 randomized phase II/III trials without inferior results regarding TTP or OS $[10,11]$. A further rationale for weekly docetaxel might be that standard-dose single-agent docetaxel (100 mg/m $\left.\mathrm{m}^{2} \mathrm{q} 3 \mathrm{w}\right)$ frequently needs to be adjusted to $75 \mathrm{mg} / \mathrm{m}^{2}$ in pretreated, unfit, or elderly patients [12].

The relatively low rate of severe leukopenia associated with weekly scheduled docetaxel may permit a combination with other cytotoxic agents. Taxanes and anthracyclines are considered among the most active single agents for the treatment of early breast cancer as well as MBC. Consequently, their combined use is a logical step in the search for highly effective chemotherapy combinations. Phase II trials which have investigated such an anthracycline/taxane combination given on a 3-week schedule have shown an improved RR of 46-88\% without a higher rate of cardiotoxicity [13-16]. The high RR were attained in patients with unfavorable prognostic factors (multiple metastatic sites, visceral involvement, and prior exposure to adjuvant chemotherapy). However, the dose-limiting factor in these trials was leukopenia. Phase II trials investigating a weekly scheduled anthracycline/taxane combination proved efficient and had a manageable toxicity profile $[17,18]$. Considering these prior experiences, the D4 study was designed to evaluate the toxicity and efficacy of a weekly docetaxel/doxorubicin regimen compared to a 3-weekly scheduled standard scheme in younger and medically fit patients with MBC.

\section{Patients and Methods}

\section{Patient Selection}

The treatment protocol was approved by the local ethics committee and all patients gave their written informed consent before treatment was started.

Patients with MBC, none of whom had received chemotherapy for metastatic disease, were recruited for the trial. Patients were required to have a Karnofsky Performance Status (KPS) $\geq 70 \%$ and an age between 18 and 65 years. Patients who had received prior adjuvant anthracyclines at a cumulative dose $\geq 200 \mathrm{mg} / \mathrm{m}^{2}$ or who had a positive history of coronary heart disease with cardiac dysfunction or an impaired left ventricular ejection fraction (EF) were not eligible; cardiac EF had to be normal ( $\geq 50 \%)$.

Patients were required to have histologically proven MBC, bidimensionally measurable disease, and an anticipated survival of at least 12 weeks. Prior to study entry, hepatic, renal, and hematological functions had to be adequate [leukocyte count $\geq 3.0 \times$ $10^{9} / \mathrm{l}$, platelets $\geq 100 \times 10^{9} / \mathrm{l}$, hemoglobin $\geq 8 \mathrm{~g} / \mathrm{dl}$, bilirubin $\leq 1.25$ times the normal range, alanine aminotransferase:aspartate aminotransferase (ALT:AST) ratio $\leq 3$ times the normal range, and alkaline phosphatase $\leq 2.5$ times the normal range].

Patients with bone metastases only and/or steroid (estrogen and/or progesterone) receptor expression without prior endocrine therapy were not eligible for the trial. Additional exclusion criteria were active infections, radiotherapy of more than $25 \%$ of marrow-containing bone, clinically overt brain metastases, previous neuropathy $\geq$ grade II, or a history of a second malignancy other than resected basal cell and/or squamous cell carcinoma of the skin.

Patients were not eligible for study enrolment if they were pregnant or lactating, or if they refused effective contraception.

\section{Treatment Regimen}

Docetaxel was dissolved in $100 \mathrm{ml}$ of $0.9 \%$ saline and given by intravenous (i.v.) infusion over $30 \mathrm{~min}\left(35 \mathrm{mg} / \mathrm{m}^{2}\right.$ weekly) or 60 $\min \left(75 \mathrm{mg} / \mathrm{m}^{2} \mathrm{q} 3 \mathrm{w}\right)$, respectively. Doxorubicin $\left(50 \mathrm{mg} / \mathrm{m}^{2}\right)$ was dissolved in $250 \mathrm{ml}$ of $0.9 \%$ saline and infused for $60 \mathrm{~min}$. 
Patients in the D4 study received doxorubicin $\left(50 \mathrm{mg} / \mathrm{m}^{2}\right)$ on the first day of treatment in addition to docetaxel given either at a 3-weekly dose of $75 \mathrm{mg} / \mathrm{m}^{2} \mathrm{q} 3 \mathrm{w}$ or at a weekly dose of $35 \mathrm{mg} / \mathrm{m}^{2}$ (days 1,8 , and 15; $\mathrm{q} 4 \mathrm{w}$ ). Treatment was continued until a maximum of 8 cycles, unacceptable toxicity, or disease progression.

All patients received standard corticosteroid prophylaxis, antiemetics (routinely 5HT3 antagonists), and growth factors (which were allowed at any point) according to the local standards.

\section{Dose Adjustments}

In case of myelosuppression on the day of the planned treatment (leukocytes $\leq 2,000 / \mu \mathrm{l}$ and platelets $\leq 50,000 / \mu \mathrm{l}$ ), further drug administration was postponed for 1 week until bone marrow recovery occurred (leukocytes $\geq 2,000 / \mu l$ and platelets $\geq 50,000 / \mu \mathrm{l})$. If there was no recovery within the additional rest of 1 week, the patient was excluded from the study. A reduced dose of each drug $(-25 \%)$ was applied in case of a leukocyte count between $2,000 / \mu \mathrm{l}$ and $3,000 / \mu \mathrm{l}$ and a platelet count between $50,000 / \mu \mathrm{l}$ and $100,000 / \mu \mathrm{l}$. A full dose of docetaxel and doxorubicin was administered if the blood counts had risen to leukocytes $\geq 3,000 / \mu \mathrm{l}$ and platelets $\geq 100,000 / \mu \mathrm{l}$.

Patients were excluded from the trial in case of nonhematological toxicity $\geq$ grade 3 (excluding alopecia and nausea/vomiting). Dose reductions of $25 \%$ (for doxorubicin and docetaxel) were required in case of hematological toxicity grade 3 or 4 complicated by fever, infection, or both. Moreover, a reduced dose $(-20 \%)$ was required in case of grade 3 diarrhea or mucositis.

\section{Data Collection}

Drug administration, KPS, and toxicity or adverse events were recorded after every cycle of treatment. Weekly blood counts were performed. Febrile neutropenia was defined as fever $\left(\geq 38^{\circ} \mathrm{C}\right)$ with grade 4 neutropenia requiring i.v. antibiotics and/or hospitalization without documented infection. Fluid retention included peripheral edema and/or pleural and pericardial effusions.

Toxicity was graded according to the National Cancer Institute's Common Toxicity Criteria (NCI CTC 2.0) [19]. Imaging studies using ultrasonography, computed tomography (CT), or magnetic resonance imaging (MRI) were performed after every 2 cycles of treatment.

\section{Cardiac Surveillance}

Patients in the D4 trial underwent echocardiography prior to study entry and then after every second cycle. An EF $\geq 50 \%$ was considered normal. Patients were excluded from the study if the EF decreased to $\leq 50 \%$ or decreased by $\geq 10 \%$ compared to the baseline value.

\section{Response Evaluation}

In all patients, tumors were measured by imaging procedures (ultrasound, CT, or MRI) within 14 days prior to study entry and subsequently after every 2 cycles of treatment. A standard evaluation comprised of history, a physical examination, and routine laboratory tests (including a complete blood cell count, chemistry profile, and electrolyte determination) was performed before each treatment.

Patient response was assessed according to standard WHO criteria as follows: Complete response (CR) was defined as the disappearance of all known disease as determined by 2 observations not less than 4 weeks apart, while partial response (PR) was defined as a decrease of at least $50 \%$ in the sum of the products of the largest perpendicular diameters of all measurable lesions as determined by 2 observations not less than 4 weeks apart. Stable disease (SD), lasting at least 6 weeks from the start of the study (i.e. the first drug administration), was defined as a $<50 \%$ decrease and $\mathrm{a}<25 \%$ increase in the sum of the products of the largest perpendicular diameters of all measurable lesions. Progressive disease (PD) was a $>25 \%$ increase in the size of at least 1 bidimensionally or unidimensionally measurable lesion or the appearance of a new lesion. The occurrence of pleural effusion was considered a sign of progression if verified by positive cytology.

\section{Study Endpoints and Statistics}

The primary study endpoint was hematotoxicity (leukopenia). Assuming grade 3 and grade 4 hematotoxicity rates of $70-95 \%$ for the standard regimen and $10-20 \%$ for the weekly regimen, the calculated sample size for the primary endpoint was 40 patients (20 for each treatment arm), with a statistical power of $80 \%$ using a $5 \%$ level of significance (Fishers's exact test).

An interim analysis was planned in 80 recruited patients (40 for each treatment arm) for the primary endpoint using $\alpha_{1}=$ 0.0052 and $\alpha_{2}=0.048$ as the levels of significance (O'Brien and Fleming sequential design).

For the secondary endpoint (TTP) the calculated sample size was 242 patients, with the assumption of the noninferiority of the weekly schedule (TTP $\mathrm{q} 3 \mathrm{w}=10.3$ months and TTP $\mathrm{q} 1 \mathrm{w}=9.3$ months) (O'Brien and Fleming sequential design). Sample sizes were calculated using NCSS/PASS 2000 software. Further secondary endpoints were OS and RR. TTP was determined by the interval between the initiation of therapy and the first date that disease progression was objectively documented. OS was measured from the date of the start of treatment to the date of death from any cause. All patients were included in the (intent-to-treat) analysis of TTP and survival.

The probabilities of survival and TTP were estimated by Kaplan-Meier analysis, and confidence intervals for the RR were calculated using methods for exact binominal confidence intervals $[20,21]$.

\section{Results}

\section{Patient Characteristics}

Patients were recruited between July 2001 and August 2008. Since the scheduled interim analysis showed failure to reach statistical significance for the primary endpoint in the final analysis, the D4 study was closed before achieving its target recruitment (85 of 242 patients). The median observation time was 18.7 months (range 0.352.3). The patients' characteristics are presented in table 1.

\section{Toxicity}

A summary of the hematological and nonhematological toxicities is given in table 2. A comparably low rate of leukopenia, i.e. $\geq$ grade 3 , which was rather similar to the one observed in the weekly arm, was observed in the 
standard q3w arm of the D4 study (per-patient analysis: $61.9 \%$ q3w vs. $65.1 \%$ q1w; $p>0.05$ ) even though the rate of grade 4 leukopenia was nearly twice the number in the standard arm (38.1\% q3w vs. 20.9 q1w).

Fever was more frequently observed in the 3-week regimen $(21.4 \%$ q3w vs. $4.7 \%$ q1w; $\mathrm{p}=0.03)$. Moreover, grade 3 and grade 4 diarrhea and infections occurred more frequently in the standard arm, whereas neurotoxicity $(7.0 \%$ $\mathrm{q} 1 \mathrm{w}$ vs. $0 \% \mathrm{q} 3 \mathrm{w} ; \mathrm{p} \geq 0.05)$ and skin/nail disorders $(11.6 \%$ $\mathrm{q} 1 \mathrm{w}$ vs. $0 \% \mathrm{q} 3 \mathrm{w} ; \mathrm{p}=0.06$ ) were observed more frequently in the weekly arm. Except for fever, none of these differences reached the 0.05 level of significance. Other nonhematological toxicities ( $\geq$ grade 3 ) were comparable between the 2 schedules.

The median number of applied cycles was 6 (range 1-8) for the standard arm and 5 (range 1-8) for the weekly arm. The median duration of treatment was 105.5 days (range 1-170) for the standard arm and 151 days (range 1-245) for the weekly schedule. Dose reductions and delayed and omitted doses within a cycle were required significantly more often in patients randomized to weekly docetaxel ( $p<0.001$, each). There was a significant difference regarding the percentage of the intended drug delivered within a cycle between the 2 regimens (99.2\% standard dose vs. $78.3 \%$ weekly dose).

\section{Efficacy}

The overall RR was $48.2 \%$ (95\% CI 37.3-59.3), with 3 CR, 38 PR, 22 SD, and 15 PD (intent-to-treat analysis) (table 3). Seven patients were not evaluable. The overall $\mathrm{RR}$ was comparable between the groups of standard or weekly scheduled docetaxel $(44.2 \%$ q1w vs. $52.4 \%$ q3w; $\mathrm{p}=0.52)$. Moreover, there was a numerical but not significant difference with regard to TTP (6.2 months q1w vs. 10.3 months $\mathrm{q} 3 \mathrm{w} ; \mathrm{p}=0.36)$ and $\mathrm{OS}(20.5$ months $\mathrm{q} 1 \mathrm{w}$ vs. 28.7 months $\mathrm{q} 3 \mathrm{w} ; \mathrm{p}=0.98$ ) (table 4 ; fig. 1 ). A summary of the response and survival data is given in tables 3 and 4 and in figure 1.

\section{Discussion}

Numerous phase II studies have shown a considerably reduced hematotoxicity, but stable efficacy, of weekly scheduled docetaxel in the first- or second-line setting of MBC [5-9]. These data have been confirmed in 2 randomized phase II/III trials by Rivera et al. [10] and Tabernero et al. [11]. This rather low rate of severe leukopenia associated with weekly scheduled docetaxel may permit its combination with anthracyclines. Both agents are
Table 1. Patient characteristics

\begin{tabular}{|c|c|c|}
\hline \multirow[t]{2}{*}{ Characteristics } & \multicolumn{2}{|c|}{$\mathrm{D} 4(\mathrm{n}=85)$} \\
\hline & $\mathrm{q} 1 \mathrm{w}$ & $\mathrm{q} 3 \mathrm{w}$ \\
\hline Patients & 43 & 42 \\
\hline \multicolumn{3}{|l|}{ Age, years } \\
\hline Median & 54 & 56 \\
\hline Range & $29-70$ & $39-70$ \\
\hline \multicolumn{3}{|l|}{ KPS, \% } \\
\hline Median & 90 & 90 \\
\hline Range & $70-100$ & $70-100$ \\
\hline \multicolumn{3}{|l|}{ Estrogen and progesterone receptor status } \\
\hline Positive & 32 & 31 \\
\hline Negative & 10 & 8 \\
\hline Unknown & 1 & 3 \\
\hline \multicolumn{3}{|l|}{ Menopausal status } \\
\hline Premenopausal & 11 & 7 \\
\hline Postmenopausal & 32 & 35 \\
\hline \multicolumn{3}{|l|}{ HER-2 status } \\
\hline Positive (IHC $3+$ or $2+$ and FISH+) & 10 & 11 \\
\hline Negative (IHC 0 or $1+$ or $2+$ and FISH-) & 22 & 26 \\
\hline Unknown & 11 & 5 \\
\hline \multicolumn{3}{|l|}{ Measurable disease sites } \\
\hline Lung & 20 & 14 \\
\hline Liver & 21 & 23 \\
\hline Lymph nodes & 22 & 15 \\
\hline Skin & 4 & 2 \\
\hline Skeleton & 21 & 15 \\
\hline \multicolumn{3}{|l|}{ Disease sites per patient, $\mathrm{n}$} \\
\hline 1 & 9 & 13 \\
\hline 2 & 11 & 18 \\
\hline$\geq 3$ & 23 & 11 \\
\hline \multicolumn{3}{|l|}{ Prior treatment } \\
\hline Adjuvant chemotherapy & 20 & 20 \\
\hline (including anthracyclines) & 11 & 7 \\
\hline Adjuvant hormonal therapy & 23 & 22 \\
\hline
\end{tabular}

considered among the most active single agents for the treatment of MBC. Consequently, their combined use is a logical step in the search for highly effective chemotherapy combinations.

Previous phase II trials investigated a 3-week scheduled anthracycline/taxane regimen with impressive high RR of 46-88\% [13-16]. However, the dose-limiting factor in these trials was leukopenia, leading to the initiation of phase II trials investigating a weekly anthracycline/taxane combination. Such studies have demonstrated efficacy with a manageable toxicity profile $[17,18]$. Gamucci et al. [17] reported a considerably low rate of $\geq$ grade 3 neutropenia of $16 \%$ of patients who received first-line weekly epirubicin $\left(25 \mathrm{mg} / \mathrm{m}^{2}\right)$ and docetaxel $\left(25 \mathrm{mg} / \mathrm{m}^{2}\right)$ for MBC. The regimen was quite effective, with an RR of 
Table 2. Toxicity profile (per-patient analysis): hematological and nonhematological toxicity by NCI CTC grade

$\begin{array}{ccccccccccc}\mathrm{A}(\mathrm{q} 3 \mathrm{w}), \% & & & \mathrm{~B}(\mathrm{q} 1 \mathrm{w}), \% & & \\ & 1 & 2 & 3 & 4 & 0 & 1 & 2 & 3 & 4\end{array}$

$\mathrm{p}$ value (after dichotomization $\leq 2 / \geq 3$ )

\begin{tabular}{|c|c|c|c|c|c|c|c|c|c|c|c|}
\hline \multicolumn{12}{|l|}{ Hematological toxicity } \\
\hline Anemia & 14.3 & 57.1 & 28.6 & 0 & 0 & 11.6 & 44.2 & 34.9 & 9.3 & 0 & $>0.05$ \\
\hline Leukopenia & 11.9 & 4.8 & 21.4 & 23.8 & 38.1 & 11.6 & 9.3 & 13.9 & 44.2 & 20.9 & $>0.05$ \\
\hline Thrombocytopenia & 71.4 & 21.4 & 4.8 & 2.4 & 0 & 58.1 & 27.9 & 6.9 & 6.9 & 0 & $>0.05$ \\
\hline \multicolumn{12}{|l|}{ Nonhematological toxicity } \\
\hline Alopecia & 14.3 & 7.1 & 78.6 & 0 & 0 & 18.6 & 9.3 & 72.1 & 0 & 0 & $>0.05$ \\
\hline $\mathrm{AP}$ & 61.9 & 35.7 & 2.4 & 0 & 0 & 62.8 & 32.6 & 4.7 & 0 & 0 & $>0.05$ \\
\hline Arrhythmias & 85.7 & 9.5 & 4.8 & 0 & 0 & 90.7 & 4.7 & 2.3 & 2.3 & 0 & $>0.05$ \\
\hline Bilirubin & 97.6 & 0 & 2.4 & 0 & 0 & 81.4 & 16.3 & 0 & 2.3 & 0 & $>0.05$ \\
\hline Constipation & 57.1 & 35.7 & 7.1 & 0 & 0 & 79.1 & 9.3 & 9.3 & 2.3 & 0 & $>0.05$ \\
\hline Creatinine & 95.2 & 2.4 & 0 & 2.4 & 0 & 88.4 & 11.6 & 0 & 0 & 0 & $>0.05$ \\
\hline Diarrhea & 50.0 & 30.9 & 14.3 & 2.4 & 2.4 & 65.1 & 23.3 & 11.6 & 0 & 0 & $>0.05$ \\
\hline Fever & 61.9 & 4.8 & 11.9 & 21.4 & 0 & 72.1 & 11.6 & 11.6 & 4.7 & 0 & 0.03 \\
\hline Fluid retention & 76.2 & 16.7 & 4.8 & 2.4 & 0 & 69.8 & 18.6 & 11.6 & 0 & 0 & $>0.05$ \\
\hline Gastrointestinal symptoms & 90.5 & 4.8 & 2.4 & 2.4 & 0 & 95.4 & 2.3 & 2.3 & 0 & 0 & $>0.05$ \\
\hline GGT & 42.9 & 26.2 & 14.3 & 14.3 & 2.4 & 46.5 & 20.9 & 6.9 & 20.9 & 4.7 & $>0.05$ \\
\hline Infections & 50.0 & 14.3 & 19.1 & 11.9 & 4.8 & 69.8 & 6.9 & 18.6 & 4.7 & 0 & $>0.05$ \\
\hline Mucositis & 50.0 & 26.2 & 16.7 & 7.1 & 0 & 34.9 & 27.9 & 27.9 & 9.3 & 0 & $>0.05$ \\
\hline Musculoskeletal disorders & 97.6 & 0 & 2.4 & 0 & 0 & 95.4 & 4.7 & 0 & 0 & 0 & $>0.05$ \\
\hline Nausea and vomiting & 30.9 & 40.5 & 19.1 & 7.1 & 2.4 & 53.5 & 20.9 & 13.9 & 11.6 & 0 & $>0.05$ \\
\hline Neurotoxicity & 61.9 & 28.6 & 9.5 & 0 & 0 & 55.8 & 23.3 & 13.9 & 4.7 & 2.3 & $>0.05$ \\
\hline Edema & 100.0 & 0 & 0 & 0 & 0 & 93.0 & 0 & 6.9 & 0 & 0 & $>0.05$ \\
\hline Pain & 35.7 & 35.7 & 21.4 & 2.4 & 4.8 & 62.8 & 16.3 & 18.6 & 2.3 & 0 & $>0.05$ \\
\hline Skin and nail disorders & 85.7 & 9.5 & 4.8 & 0 & 0 & 60.5 & 18.6 & 9.3 & 9.3 & 2.3 & $>0.05$ \\
\hline
\end{tabular}

Table 3. Efficacy: RR (intent-to-treat analysis)

\begin{tabular}{lllrllll}
\hline D4 & CR & PR & SD & PD & Not evaluable & RR, \% & $95 \%$ CI, \% \\
\hline All patients $(\mathrm{n}=85)$ & 3 & 38 & 22 & 15 & 7 & 48.2 & $37.3-59.3$ \\
q1w group ( $\mathrm{n}=43)$ & 1 & 18 & 9 & 10 & 5 & 44.2 & $29.1-60.1$ \\
q3w group ( $\mathrm{n}=42)$ & 2 & 20 & 13 & 5 & 2 & 52.4 & $36.4-68.0$ \\
\hline
\end{tabular}

${ }^{a}$ RR q1w versus q3w.

$60 \%$ and a median OS of 25 months. Moreover, PerezManga et al. [18] reported on a phase II study which investigated a combination of doxorubicin $\left(50 \mathrm{mg} / \mathrm{m}^{2} \mathrm{q} 4 \mathrm{w}\right)$ and weekly scheduled docetaxel $\left(36 \mathrm{mg} / \mathrm{m}^{2}\right.$ days 1,8 , and 15 ; q4w) for locally advanced or metastatic breast cancer (first line). A consistently low rate of severe neutropenia ( $\geq$ grade 3 ) was reported ( $<10 \%$ febrile neutropenia) and RR were considerably high among locally advanced and metastasized patients, i.e. 93 and 64\%, respectively.

Lacking randomized data, the D4 study was designed to evaluate the toxicity and efficacy of a weekly docetaxel/ doxorubicin regimen compared to the 3-weekly standard scheme in younger and medically fit MBC patients.

In brief, in the primary safety endpoint of the $\mathrm{D} 4$ study a significant difference was not reached. The assumption of a markedly reduced hematotoxicity within the weekly schedule was not verified. Surprisingly, the rate of leukopenia ( $\geq$ grade 3 ) was rather low in the standard arm, whereas it was not reduced at all in the weekly arm (61.9\% $\mathrm{q} 3 \mathrm{w}$ vs. $65.1 \% \mathrm{q} 1 \mathrm{w} ; \mathrm{p}>0.05)$. Since the primary endpoint was not reached, the D4 study was closed after an interim analysis according to the study protocol (85 of 242 
Fig. 1. TTP and OS in the D4 study. mo = Months.

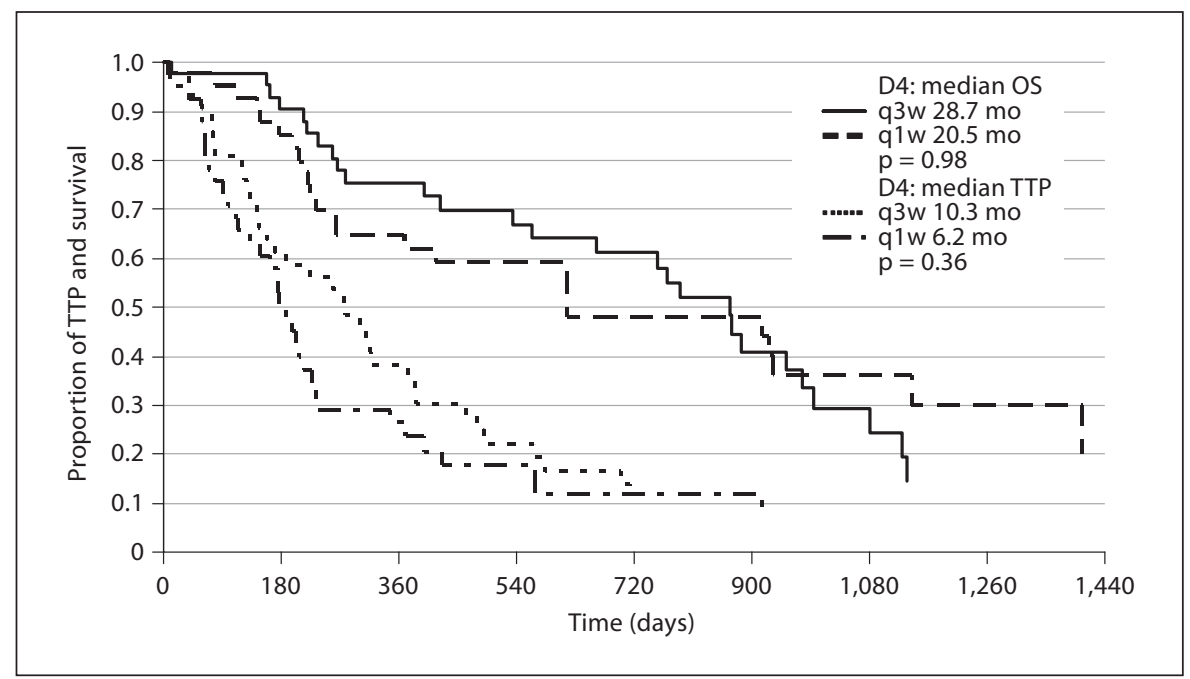

patients). The presumption of a greatly reduced hematotoxicity in the weekly arm was based on the studies of Perez-Manga et al. [17] and Gamucci et al. [18]. Both investigated a weekly scheduled anthracycline/taxane combination which has shown a reduced rate of leukopenia. Thus, we cannot provide a valuable explanation for the relatively high numbers of grade 3 and 4 leukopenia in the weekly docetaxel arm observed in our study.

With regard to nonhematological toxicities, i.e. skin and nail disorders, the known sequelae of weekly administered docetaxel were increased in patients who were randomized to the weekly schedule $(11.6 \% \mathrm{q} 1 \mathrm{w}$ vs. $0 \%$ $\mathrm{q} 3 \mathrm{w} ; \mathrm{p}=0.06$ ). Moreover, even more surprisingly, the rate of reduced, delayed, or omitted doses within a cycle was significantly higher among patients receiving weekly docetaxel as follows: 38.3 versus $23.3 \%, 31.1$ versus $10.6 \%$, and 21.9 versus $0 \%$, respectively ( $q 1 \mathrm{w}$ vs. $\mathrm{q} 3 \mathrm{w} ; \mathrm{p}<0.001$, each). Therefore, the percentage of the intended drug delivered within a cycle was greatly reduced in the weekly $\operatorname{arm}(77.3 \%$ q1w vs. $90.3 \% \mathrm{q} 3 \mathrm{w}$ ) (table 5).

It is suspected that this lesser dose contributed to a measurable loss of efficacy even though none of the differences in RR, TTP, and OS reached the level of significance. The RR was $44.2 \%$ in the weekly arm compared to $52.4 \%$ under the standard regimen $(\mathrm{p}=0.52)$. Moreover, the median TTP and OS were numerically inferior in patients who received the weekly schedule. TTP was 6.2 (q1w) versus $10.3(\mathrm{q} 3 \mathrm{w})$ months $(\mathrm{p}=0.36)$, and OS was $20.5(\mathrm{q} 1 \mathrm{w})$ versus $28.7(\mathrm{q} 3 \mathrm{w})$ months $(\mathrm{p}=0.98)$.

A final statement regarding efficacy is restricted by the limitation that the calculated sample size for the second-

D4 - Combined Weekly Docetaxel for $\mathrm{MBC}$
Table 4. Efficacy: TTP and OS

\begin{tabular}{|c|c|c|c|c|c|}
\hline \multirow[t]{2}{*}{ D4 } & \multicolumn{2}{|l|}{$q 3 w$} & \multicolumn{2}{|l|}{$\mathrm{q} 1 \mathrm{w}$} & \multirow{2}{*}{$\begin{array}{l}\text { p value } \\
\text { (log-rank } \\
\text { test) }\end{array}$} \\
\hline & median & range & media & range & \\
\hline TTP, months & 10.3 & $1.3-23.8$ & 6.2 & $0.2-30.5$ & 0.36 \\
\hline OS, months & 28.7 & $0.4-37.9$ & 20.5 & $0.3-46.8$ & 0.98 \\
\hline
\end{tabular}

Table 5. Toxicity profile: dose modifications

\begin{tabular}{|c|c|c|c|c|}
\hline & $\begin{array}{l}\text { All } \\
(\mathrm{n}=432)\end{array}$ & $\begin{array}{l}q 3 \mathrm{w} \\
(\mathrm{n}=236)\end{array}$ & $\begin{array}{l}\text { q1w } \\
(\mathrm{n}=196)\end{array}$ & $\mathrm{p}$ value \\
\hline \multicolumn{5}{|l|}{ Cycles } \\
\hline Dose reductions $s^{\mathrm{a}}$ & $130(30.09)$ & $55(23.31)$ & $75(38.27)$ & $<0.001$ \\
\hline Delayed doses ${ }^{\mathrm{a}}$ & $86(19.91)$ & $25(10.59)$ & $61(31.12)$ & $<0.001$ \\
\hline Omitted doses $^{\mathrm{a}}$ & $43(9.95)$ & 0 & $43(21.94)$ & $<0.001$ \\
\hline \multicolumn{5}{|c|}{ Percentage of intended } \\
\hline drug delivery & 84.29 & 90.25 & 77.30 & $<0.001$ \\
\hline
\end{tabular}

${ }^{a}$ Reductions within a cycle; data given as n (\%).

ary endpoints (TTP and OS) was not reached in the D4 study. Moreover, imbalances regarding the cumulative anthracycline dose between both study arms may contribute to a bias regarding the efficacy parameters (50 $\mathrm{mg} / \mathrm{m}^{2}$ doxorubicin applied $\mathrm{q} 3 \mathrm{w}$ in the 'standard arm' vs. q4w in the 'weekly arm'). Nevertheless, the study was ter- 
minated after the interim analysis due to failure to reach statistical significance in the primary endpoint (leukopenia). The striking trend towards an improved TTP and OS within the standard arm of the D4 study (q3w vs. q1w: TTP 10.3 vs. 6.2 months and OS 28.7 vs. 20.5 months) may be - at least partially - explained by the above mentioned limitations.

In conclusion, the data of the D4 study have surprisingly but unmistakably shown that leukopenia could not be prevented by a weekly schedule of a docetaxel/anthracycline combination despite phase II data indicating a greatly reduced hematotoxicity in favor of the weekly administration of docetaxel. In view of the at least numerically reduced efficacy in the weekly arm as well as the substantially increased nonhematological side effects, this approach seems not to merit further investigation.

\section{References}

1 Chan S, Friedrichs K, Noel D, Pinter T, Van Belle S, Vorobiof D, Duarte R, Gil Gil M, Bodrogi I, Murray E, Yelle L, von Minckwitz G, Korec S, Simmonds P, Buzzi F, Gonzalez Mancha R, Richardson G, Walpole E, Ronzoni M, Murawsky M, Alakl M, Riva A, Crown J: Prospective randomized trial of docetaxel versus doxorubicin in patients with metastatic breast cancer. J Clin Oncol 1999;17:2341-2354

2 Bonneterre J, Roche H, Monnier A, Guastalla JP, Namer M, Fargeot P, Assadourian S: Docetaxel versus 5 -fluorouracil plus vinorelbine in metastatic breast cancer after anthracycline therapy failure. Br J Cancer 2002;87: 1210-1215.

3 Nabholtz JM, Senn HJ, Bezwoda WR, Melnychuk D, Deschenes L, Douma J, Vandenberg TA, Rapoport B, Rosso R, Trillet-Lenoir V, Drbal J, Molino A, Nortier JW, Richel DJ, Nagykalnai T, Siedlecki P, Wilking N, Genot JY, Hupperets PS, Pannuti F, Skarlos D, Tomiak EM, Murawsky M, Alakl M, Aapro M, et al: Prospective randomized trial of docetaxel versus mitomycin plus vinblastine in patients with metastatic breast cancer progressing despite previous anthracyclinecontaining chemotherapy - 304 study group. J Clin Oncol 1999;17:1413-1424.

4 Sjostrom J, Blomqvist C, Mouridsen $\mathrm{H}$, Pluzanska A, Ottosson-Lonn S, Bengtsson NO, Ostenstad B, Mjaaland I, Palm-Sjovall M, Wist E, Valvere V, Anderson H, Bergh J: Docetaxel compared with sequential methotrexate and 5-fluorouracil in patients with advanced breast cancer after anthracycline failure: a randomised phase III study with crossover on progression by the Scandinavian Breast Group. Eur J Cancer 1999;35: 1194-1201.

5 Hainsworth JD, Burris HA 3rd, Greco FA: Weekly administration of docetaxel (Taxotere): summary of clinical data. Semin Oncol 1999;26:19-24.

6 Aihara T, Kim Y, Takatsuka Y: Phase II study of weekly docetaxel in patients with metastatic breast cancer. Ann Oncol 2002;13: 286-292.
7 Stemmler J, Mair W, Stauch M, Papke J, Deutsch G, Abenhardt W, Dorn B, Kentenich C, Malekmohammadi M, Jackisch C, Leinung S, Brudler O, Vehling-Kaiser U, Stamp J, Heinemann V: High efficacy and low toxicity of weekly docetaxel given as first-line treatment for metastatic breast cancer. Oncology 2005;68:71-78.

8 Stemmler HJ, Gutschow K, Sommer H, Malekmohammadi M, Kentenich CH, Forstpointner R, Geuenich S, Bischoff J, Hiddemann W, Heinemann V: Weekly docetaxel (Taxotere) in patients with metastatic breast cancer. Ann Oncol 2001;12:13931398.

9 Burstein HJ, Manola J, Younger J, Parker LM, Bunnell CA, Scheib R, Matulonis UA, Garber JE, Clarke KD, Shulman LN, Winer EP: Docetaxel administered on a weekly basis for metastatic breast cancer. J Clin Oncol 2000; 18:1212-1219.

10 Rivera E, Mejia JA, Arun BK, Adinin RB, Walters RS, Brewster A, Broglio KR, Yin G, Esmaeli B, Hortobagyi GN, Valero V: Phase 3 study comparing the use of docetaxel on an every-3-week versus weekly schedule in the treatment of metastatic breast cancer. Cancer 2008;112:1455-1461.

11 Tabernero J, Climent MA, Lluch A, Albanell J, Vermorken JB, Barnadas A, Anton A, Laurent C, Mayordomo JI, Estaun N, Losa I, Guillem V, Garcia-Conde J, Tisaire JL, Baselga J: A multicentre, randomised phase II study of weekly or 3-weekly docetaxel in patients with metastatic breast cancer. Ann Oncol 2004;15:1358-1365.

12 Salminen E, Bergman M, Huhtala S, Ekholm E: Docetaxel: standard recommended dose of $100 \mathrm{mg} / \mathrm{m}(2)$ is effective but not feasible for some metastatic breast cancer patients heavily pretreated with chemotherapy - a phase II single-center study. J Clin Oncol 1999;17: 1127

13 Mavroudis D, Alexopoulos A, Ziras N, Malamos N, Kouroussis C, Kakolyris S, Agelaki S, Kalbakis K, Tsavaris N, Potamianou A, Rigatos G, Georgoulias V: Front-line treatment of advanced breast cancer with docetaxel and epirubicin: a multicenter phase II study. Ann Oncol 2000;11:1249-1254.
14 Pagani O, Sessa C, Nole F, Crivellari D, Lombardi D, Thurlimann B, Hess D, Borner M, Bauer J, Martinelli G, Graffeo R, Zucchetti M, D’Incalci M, Goldhirsch A: Epidoxorubicin and docetaxel as first-line chemotherapy in patients with advanced breast cancer: a multicentric phase I-II study. Ann Oncol 2000;11:985-991.

15 Milla-Santos A, Milla L, Rallo L, Solano V: High-dose epirubicin plus docetaxel at standard dose with lenograstim support as firstline therapy in advanced breast cancer. Am J Clin Oncol 2001;24:138-142.

16 Morales S, Lorenzo A, Ramos M, Ballesteros P, Mendez M, Almanza C, Castellanos J, Moreno-Nogueira JA, Casal J, Lizon J, Oltra A, Frau A, Machengs I, Galan A, Belon J, Llorca C: Docetaxel plus epirubicin is a highly active, well-tolerated, first-line chemotherapy for metastatic breast cancer: Results of a large, multicentre phase II study. Cancer Chemother Pharmacol 2004;53:7581.

17 Gamucci T, D’Ottavio AM, Magnolfi E, Barduagni M, Vaccaro A, Sperduti I, Moscetti L, Belli F, Meliffi L: Weekly epirubicin plus docetaxel as first-line treatment in metastatic breast cancer. Br J Cancer 2007;97:10401045

18 Perez-Manga G, Lopez P, Sancho J, Mendez M, Cassinello J, Dominguez S, Enrech S, Palomero M, Menendez P, Quiben R, LopezMartin J: Phase II study of weekly docetaxel and doxorubicin as first-line treatment of locally advanced or metastatic breast cancer: preliminary results. Proc Am Soc Clin Oncol 2000;19:407.

19 Ajani JA, Welch SR, Raber MN, Fields WS, Krakoff IH: Comprehensive criteria for assessing therapy-induced toxicity. Cancer Invest 1990;8:147-159.

20 Kaplan EL, Meier P: Nonparametric estimation from incomplete observations. J Am Stat Assoc 1959;53:457-481.

21 Cox DR: The Analysis of Binary Data. London, Methuen, 1970. 